\title{
A América Latina nos jornais brasileiros alternativos Opinião e Movimento (1972-1976)
}

\section{Latin America in Brazilian newspapers Alternative Opinion and Movement (1972- 1976)}

\author{
Antonio Hohlfeld ${ }^{1}$ \\ (hohlfeldt@yahoo.com.br) \\ Elisa Casagrande \\ (elisacasagrande@gmail.com) \\ Júlia Manzano ${ }^{2}$ \\ (juliamanzano@gmail.com)
}

http://dx.doi.org/10. 5216/cei.v15i1.22492

\begin{abstract}
Resumo
Uma análise comparativa de dois jornais alternativos brasileiros: Opinião e Movimento - entre os anos de 1972 a 1976, que permite visualizar como tais publicações informaram a respeito dos acontecimentos ocorridos na América latina durante a ditadura brasileira. Ao mesmo tempo, a pesquisa permite que se conheça um pouco deste jornalismo de combate, que se aproxima da prática histórica do publicismo.
\end{abstract}

Palavras-chave: Opinião. Movimento. História da imprensa brasileira. América Latina. Teoria do Jornalismo.

\begin{abstract}
A comparative analysis of two alternative newspapers Brazilians, Opinion and Movement covering the years 1972 to 1976, displays such as publications, during the Brazilian dictatorship, informed about the events in Latin America. At the same time, the survey allows us to know a little of this combat journalism, which approximates the historical practice of publicismo.
\end{abstract}

Keywords: Opinion. Movement. History of the Brazilian press. Latin America. Theory of Journalism.

\section{Introdução}

Durante o período da ditadura implantada no Brasil, em 1964, e aprofundada com o chamado Ato Institucional $n^{\circ} 5$, de dezembro de 1968, o país sofreu um dos mais rígidos e radicais

\footnotetext{
${ }^{1}$ Professor do Programa de Pós-Graduação em Comunicação Social da Pontifícia Universidade Católica do Rio Grande do Sul, Coordenador do NUPECC- Núcleo de Pesquisa em Ciências da Comunicação da PUCRS e Pesquisador do CNPq.

${ }^{2}$ Alunas de iniciação científica, vinculadas ao NUPECC.
}

Comun. \& Inf., v. 15, n. 1, p. 06-20, jan./jun. 2012 
controles sociais e policiais, que se refletia também no controle da censura em relação a todas as expressões artísticas e de meios de comunicação. Já são clássicos estudos como os de Paolo Marconi (1980), além de pesquisas variadas, que vem sendo realizadas ao longo dos últimos anos (HOHLFELDT, 1991; HOHLFELDT, 1999; SMITH, 2000; ALBIN, 2002; MATTOS, 2005; MELO, 2007; SOARES, 2011). Não obstante, a sociedade brasileira soube se organizar de modo a garantir a circulação da informação, mesmo que se enfrentassem dificuldades e riscos inclusive de integridade física. Nasceu, assim, aquilo que o escritor e jornalista João Antonio designou como imprensa nanica, no jornal Pasquim (1975), imediatamente estendida a toda a imprensa alternativa, isto é, jornais que dependiam essencialmente do assinante e não da publicidade, como a chamada imprensa industrial (MAIA in CARNEIRO, 2002, p. 5). Esta imprensa alternativa chegou a somar mais de 800 títulos, segundo o Catálogo da imprensa alternativa do Centro de Imprensa e Cultura Popular da Secretaria Municipal de Cultura do Rio de Janeiro (SMITH, 2000, p. 59 e 222 - nota 28; HOHLFELDT, 2011).

\section{Censura x militância jornalística}

Duas das publicações que tiveram maior repercussão, pela qualidade, pela organização e pela longevidade, foram os jornais Opinião e Movimento, ambos dirigidos pelo jornalista Raimundo Pereira, sendo que, iniciado em 23 de outubro de 1972, Opinião contou com aquele profissional até 28 de abril de 1975 (CEDAP). Uma crise entre um grupo de profissionais e o proprietário da publicação, o empresário Fernando Gasparian, fez com que este grupo deixasse o jornal e se organizasse em cooperativa, fundando Movimento, que começou a circular em 30 de junho de 1975 (HOHLFELDT, 2011). Ambas as publicações foram severamente controladas e perseguidas pelos censores e a Polícia Federal: Opinião fechou suas portas em 8 de abril de 1977 e Movimento teve suspensa a censura, no processo de abertura, desenvolvida pelo Governo Federal, após 153 edições, em 5 de junho de 1978, circulando, ainda, até 23 de novembro de 1981 (AZEVEDO, 2011), num total de 334 edições.

No âmbito de um projeto de pesquisa sobre a história do jornalismo luso-brasileiro $\left(\right.$ HOHLFELDT, 2008) ${ }^{3}$, vem-se estudando a história dessas publicações. Até o momento, dedicou-

\footnotetext{
3 Trata-se de projeto iniciado enquanto estágio Pós-Doutoral, financiado pela CAPES, em 2008, na Universidade Fernando Pessoa (Porto, Portugal), sobre a imprensa colonial de expressão portuguesa. De volta ao Brasil, o pesquisador apresentou projeto ao CNPq, então aprovado (2008) e referendado recentemente (2012), sobre uma história do jornalismo luso-brasileiro. Os resultados destes
}

Comun. \& Inf., v. 15, n. 1, p. 06-20, jan./jun. 2012 
se especial atenção a Movimento, mas este artigo pretende fazer um pequeno avanço: ninguém ignora que os acontecimentos políticos brasileiros não constituíram fato isolado no continente latino-americano, e muito especialmente no chamado Cone Sul. Sucessivamente, Argentina, Uruguai, Brasil e Chile sofreram golpes militares que instalaram ditaduras mais ou menos sangrentas. O Paraguai já vinha de uma ditadura institucionalizada há décadas (CAPARELLI, 1976). Portanto, havia um paralelismo de situações e contextos, motivo pelo qual ficou-se curioso em saber como este panorama aparecia na página desses jornais. Assim, propôs-se refletir, neste estudo, de maneira comparativa, e levando-se em conta que ambos os jornais, em seus primeiros tempos, tiveram um mesmo profissional como editor, sobre a maneira pela qual o continente latinoamericano aparecia nas páginas de tais publicações. Deve-se ter em conta que, de modo geral, o Brasil sempre esteve de costas para o continente. Culturalmente, sempre estivemos mais preocupados com a Europa - especialmente Paris - e os Estados Unidos - processo que se inicia em torno dos anos 1920, com a industrialização brasileira e que se reflete, claramente, nas crônicas de João do Rio, por exemplo.

Registre-se, de passagem, que foi justamente neste momento difícil que, contraditoriamente - ou não - intelectuais brasileiros se aproximaram do espaço hispano-americano, primeiro, talvez movidos pelo processo de exílios: militantes de outros países buscaram o Brasil; exilados brasileiros dirigiram-se especialmente para o Chile, pelo menos até setembro de 1973, durante o curto período do governo socialista de Salvador Allende. Por outro lado, Cuba, que havia sido isolada na OEA Organização dos Estados Americanos, por pressão norte-americana, recebendo apoio apenas do México, começava a despertar interesse. A Casa de las Americas, principal instituição cultural daquele país, não apenas passou a convidar intelectuais brasileiros para compor seus júris de prêmios literários, quanto instituiu um prêmio específico para a produção brasileira ${ }^{4 \square}$

\section{Opinião e Movimento}

Assim, propõem-se examinar os seis primeiros meses de circulação de cada um dos dois jornais, verificando se e que tipo de noticiário foi divulgado, naqueles períodos, por ambas as publicações. Tem-se claro que, cronologicamente, os tempos são diversos: Opinião vai cobrir o

estudos encontram-se no portal www.pucrs.br/famecos/nupecc, desenvolvido com bolsas de iniciação científica financiadas pela própria PUCRS, CNPq, CAPES e FAPERGS.

${ }^{4}$ Pessoalmente, tive a oportunidade de integrar este júri, em 1978.

Comun. \& Inf., v. 15, n. 1, p. 06-20, jan./jun. 2012 
período de 1972 e 1973, enquanto Movimento_referir-se-á ao período de 1975 e 1976. Contudo, a opção metodológica leva em conta, como se disse, o fato de ambos os jornais se colocarem na tradição do chamado publicismo, isto é, aquela linha de jornalismo surgido logo nos primeiros anos do século XVIII, na Inglaterra, através de publicações como The Tatler, (1709), The Examiner (1710), The Spectator (1711), The Guardian (1713), etc. O publicismo, para Francisco Rüdiger, caracteriza-se pelo fato de que seus textos "tinham forte cunho doutrinário, consistindo em matérias opinativas sobre questões públicas, comentários ideológicos e polêmicas com os adversários de publicidade" (RÜDIGER, 1993, p. 15; RÜDIGER, 1998, p. 11). Com certa flexibilidade, podemos conceber esses jornais como filiados a essa tendência da publicística - Publizistik, em alemão (GROTH, 2011). No entanto, Opinião, devido até mesmo a sua gênese, vinculado ao empresário Fernando Gasparian, tinha uma visão mais liberal, cobrindo um noticiário mundial, graças a serviços que adquirira de publicações como Le Monde, The Guardian, The Washignton Post, The New Yrok review of books e New Statesman, além de agências noticiosas independentes, como a Latin American News. Movimento tinha um foco mais voltado para a cobertura da política dos partidos e governos de esquerda e/ou revolucionários. Neste sentido, Movimento deu especial atenção à cobertura dos acontecimentos da América Latina, valendo-se de fontes diferentes daquelas que usualmente os jornais da imprensa de referência utilizam, como as agências Latin American News ${ }^{5}$, IPS (Inter Press Service) ${ }^{6}$ ou revistas como Afrique-Asie, Nuevo Hombre e El periodista. Ambos os jornais são tablóides, na tradição da imprensa inglesa, com cerca de 28 páginas por edição semanal. Organizam-se por editorias, sendo que a editoria cultural teve, em ambas as publicações, uma importância significativa (MARQUARDT, 2011; HOHLFELDT, 2010). Neste caso, porém, vai-se examinar a maneira pela qual a América Latina aparece em seu noticiário.

Lançado em 1972, Opinião foi o mais político dos alternativos. Era financiado pelo empresário Fernando Gasparian, que também adquiriu a revista Argumento, dedicada a temas literários, e que durou apenas 4 edições, sendo imediatamente proibida. Gasparian ainda era proprietário da editora Paz e Terra. Gasparian queria um jornal de idéias e de debate intelectual, inspirado no semanário inglês The New Statesman. Para o cargo de editor, foi convidado o jornalista

\footnotetext{
5 Mais conhecida como Prensa Latina, foi criada em 1959, por iniciativa de Ernesto Che Guevara, logo após a vitória da Revolução Cubana, e inicialmente organizada pelo jornalista argentino Jorge Ricardo Masetti. Trabalharam nela, dentre outros, Gabriel Garcia Marquez, Rodolfo Walsh, Leonardo Acosta, etc.

6 A IPS foi fundada em 1964 pelo economista Roberto Savio e pelo cientista político Pablo Piacentini, ambos argentinos, com o objetivo de trabalhar temas como o desenvolvimento social, defesa ambiental e direitos humanos. Sua formação original era cooperativada.
}

Comun. \& Inf., v. 15, n. 1, p. 06-20, jan./jun. 2012 
Raimundo Pereira, que tivera uma passagem brilhante em Amanhã, Folha da Tarde, Realidade e Veja. A decisão de colocar a política em primeiro lugar criou alguns obstáculos para Opinião, mas as primeiras edições não tiveram grandes problemas com a censura, até a edição 8, chegando a vender 40 mil exemplares. Em pouco tempo, despontou como um sério concorrente das grandes publicações. A estratégia para a rápida aceitação do público era procurar temas candentes, analisados por colaboradores de peso como Fernando Henrique Cardoso, Aloysio Biondi, Chico de Oliveira, Celso Furtado, Paul Singer e Luciano Martins. A credibilidade do jornal era grande, reforçada pela publicação de matérias de jornais respeitados internacionalmente, como Le Monde, New York Review of Books, The Washington Post e The Guardian. Aliás, foi num desses suplementos que Opinião divulgou, em primeira mão e com exclusividade, no Brasil, a transcrição das gravações em torno do caso Watergate, envolvendo o presidente norte-americano Richard Nixon. Opinião encontrava leitores em todo o país, principalmente entre empresários, intelectuais e estudantes universitários. Passou a editar, em $1^{\text {o }}$ de maio de 1975, os Cadernos Opinião, logo proibidos, mas sucedidos por Ensaios de Opinião, cuja característica era estampar a numeração antiga somada à nova, em sua capa (RIBEIRO, 2011). Uma das primeiras campanhas nacionais desenvolvidas por Opinião foi a favor da anistia política. Quando de seu fechamento, Opinião escrevia: "Este é o último número de Opinião a circular sob o regime de censura prévia. Só voltaremos a circular quando estivermos inteiramente livres de censura. Isto é, LIVRES (...). Se chegamos, agora, ao fim desta etapa, se interrompemos, com este número, nosso contato com os leitores é que uma censura obstinada e destruidora já conseguia barrar-nos todos os caminhos; já nos vedava a própria transcrição de notícias amplamente divulgadas pela imprensa diária. (...) Nos quatro e meio anos de existência do jornal os 230 números que publicamos somaram 5.796 páginas impressas. Se acrescentarmos a este número as matérias vetadas pela censura, teríamos publicado um total de 10.548 páginas. É que precisávamos fazer semanalmente, para cada jornal publicado, quase dois. (...) Arcaríamos, ainda assim, com o prejuízo, faríamos todos os sacrifícios necessários para manter Opinião nas bancas, nas mãos dos leitores, dos congressistas, do povo, de todos aqueles que partilhavam da nossa reflexão sobre os problemas do país. Mas que jornal estávamos nós passando a propor ao público? Que Opinião era essa que oferecíamos, mutilada, aviltada, desfigurada? Que matéria para meditação podíamos oferecer quando não mais podíamos sequer transcrever notícias já publicadas ou frases pronunciadas pelo presidente da República? (...)Talvez por termos sido nós, precisamente, a primeira publicação que recorreu contra a censura e que 
desvendou os mecanismos em que se firmava. (...) Desde então a censura nos dedicou uma atenção toda especial. O preço que pagamos foi o de conviver, até hoje, com a censura prévia, com o veto a alguns de nossos melhores colaboradores, com a paulatina erosão dos temas que nos eram permitidos, com a destruição do estilo, da qualidade dos nossos textos submetidos a uma censura freqüentemente bronca e sempre surda a qualquer apelo. Aqui, portanto, fazemos nossas despedidas da censura" (OPINIÃO, 8.4.1977).

Opinião era um jornal tablóide, com 28 páginas a cada edição. Formalmente, pertencia à Editora Inúbia, com sede na rua Abade Ramos, 78, jardim Botânico, no Rio de Janeiro. Suas páginas mediam $28 \mathrm{~cm}$. de largura por $36,5 \mathrm{~cm}$. de altura. Sua mancha tipográfica recuava, nos quatro lados, cerca de um centímetro em relação às bordas do papel. O jornal não utilizava fotografia. Suas ilustrações eram bicos-de-pena, bastante densos e pesados: a arte tinha a responsabilidade de Valdir de Oliveira e Cássio Loredano, de tendência expressionista. A capa apresentava o nome da publicação em caixa baixa, com imenso destaque, no alto da página, mas deixando em geral um vazado acima do nome para alguma manchete. Abaixo do título vinha a indicação da data, número de edição e preço do exemplar. A diagramação aproximava-se mais de uma revista do que de um jornal propriamente dito. Suas páginas eram distribuídas normalmente em cinco colunas, com separação em serrifa e eventual uso de boxes para destacar alguma matéria. Também aqui, as ilustrações eram pequenos desenhos.

Quanto a Movimento, teve uma edição zero a 30 de junho de 1975. Inaugurava, ao mesmo tempo, uma seção que se tornaria referencial em sua publicação, "Cena brasileira" ou "Estórias brasileiras”. Segundo Maurício Maia, a matéria aí inserida, assinada por Aguinaldo Silva, abordava um quebra-quebra ocorrido nos trens da Central do Brasil. O repórter cobria detalhadamente o acontecimento, o que bastou para que, a 2 de julho, o então Ministro da Justiça, Armando Falcão, comunicasse ao Presidente da República, Ernesto Geisel, que determinara a apreensão da futura edição do dia 7, instaurando um inquérito policial, com base na Lei de Segurança Nacional e estabelecendo censura prévia à nova publicação (MAIA in CARNEIRO, 2002, p. 471-2). Movimento foi o único jornal que já nasceu com a censura prévia decretada sobre sua cabeça. De 7 de julho de 1975 a 5 de junho de 1978, sofreu constantes represálias e cortes em suas matérias (AQUINO in CARNEIRO, 2002, p. 530). Suas 153 primeiras edições tiveram de ser enviadas semanalmente a Brasília, para exame dos censores, sendo a operação de análise e cumprimento das determinações policiais sempre custosa e demorada, gerando problemas constantes para seus 
responsáveis, os jornalistas Antonio Carlos Ferreira e Raimundo Rodrigues Pereira (SMITH, 2000, p. 88), que chegaram a ser processados diversas vezes, com base naquela mesma Lei de Segurança Nacional (MARCONI, 1980, p. 76), ainda depois de levantada a censura prévia, em julho de 1978 (MAIA in CARNEIRO, 2002, p. 504). Movimento nasceu de um racha na redação de Opinião, voltaria a dividir-se, mais tarde, gerando o jornal Em Tempo.

Movimento trazia um programa muito claro de trabalho, conforme o manifesto da edição Zero: propunha-se, não só a descrever o mundo, quanto a ajudar a transformá-lo. Para isso, criticava fortemente as grandes empresas jornalísticas, não apenas por serem empresas quanto, segundo os responsáveis pela publicação, terem se rendido às decisões da censura. Movimento propunha-se ser popular, no sentido da busca de uma linguagem menos acadêmica e de escolher focos temáticos que eventualmente interessassem a uma maior parcela da população potencialmente leitora de uma publicação semelhante (AGUIAR in CARNEIRO, 2002, p. 409).

O jornal apresentava-se em formato tablóide, em páginas de $28 \mathrm{~cm}$. de largura por $36,5 \mathrm{~cm}$. de altura. A mancha tipográfica era recuada um centímetro em cada um dos quatro lados da página. O título colocava-se isolado, no alto, em caixa alta. Abaixo da mancha tipográfica, à esquerda, indicavam-se as praças em que havia preço diferenciado do jornal. Na direita, aparecia o número da edição, preço do exemplar e data de circulação, em letras pequenas, de corpo 12 em negrito. Cada edição tinha, em média, 28 páginas, o que era um verdadeiro desafio para a sua redação, uma vez que o jornal sofreu censura prévia desde a sua edição zero. E se, nos primeiros tempos, era censurado diretamente em São Paulo, onde tinha sua sede (Rua Virgílio de Carvalho Pinto, 625, bairro Pinheiros), logo depois tinha de ser enviado para Brasília, numa operação extremamente difícil do fluxo de sua editoração.

\subsection{Os dispositivos jornalísticos}

Para a análise da cobertura de Opinião e Movimento à América Latina, constituiu-se o seguinte corpus:

$\rightarrow \quad 53$ textos de Opinião, caracterizados como $\operatorname{artigos/comentários~ou~entrevistas~}^{7}$;

$\rightarrow 96$ textos de Movimento, caracterizados como notícias, artigos/comentários, reportagens, entrevistas e pequenas notas.

\footnotetext{
7 Utilizamos, como referencial de conceituação, as obras de José Marques de Melo (1985 e 1987).
} 
Verificou-se, com clareza, uma primeira distinção: enquanto Opinião trabalha mais com o artigo de fundo, contando, para isso, com as edições internacionais de Le Monde ou The Guardian, além de artigos variados que recebe sob licença ${ }^{8}$, Movimento prefere um noticiário que é, ao mesmo tempo, informativo e interpretativo, contando com um extenso corpo de jornalistas especializados nos temas abordados, ainda que não dispense agências de notícias alternativas, como a Prensa Latina, como já referimos antes ${ }^{9}$.

Para realizar a análise proposta, buscou-se a teoria de Maurice Mouillaud a respeito dos dispositivos que caracterizam toda e qualquer publicação. Maurice Mouillaud (MOUILLAUD et PORTO, 2002, p. 29 e ss.) mostra que um jornal não se limita a informar/noticiar. Ele se organiza a partir do que o autor denomina dispositivos, como que embalagens que dão um outro sentido (melhor, mais profundo, crítico, etc.) ao que se lê/escreve, assim como, no rádio, o noticioso depende da entonação com que o locutor lê seu texto ${ }^{10}$. Mais que isso, "os dispositivos são encaixados uns nos outros" (p. 32), de modo que estes encaixes, mais as relações entre textos e dispositivos, por sua dinamicidade, permitem outras leituras. Para o pesquisador, "os dispositivos são lugares materiais ou imateriais nos quais de inscrevem (necessariamente) os textos (despachados de agências, jornal, livro, rádio, televisão, etc....)” (p. 34), possuindo formas específicas que correspondem a um "modo de estruturação do espaço e do tempo" (p. 35). Neste sentido, "o dispositivo não é um suporte, mas uma matriz que impõe suas formas aos textos (uma conversão informal se inscreve nas formas da conversação, como variante de um paradigma" (p. $34)$.

Maurice Mouillaud destaca, dentre os principais dispositivos, o título da publicação, as manchetes e os títulos de artigos/colunas, etc. Neste caso, o título da publicação é um claro indicativo do que ela almeja: opinião traduz a expressão de um posicionamento a respeito de determinado acontecimento, enquanto movimento indica dinamicidade, a busca por uma cobertura ampla, variedade que traga ao leitor a maior amplitude possível de informações do mundo, do continente, do país.

\footnotetext{
8 O que pressupõe um leitor já informado do que está ocorrendo.

9 O jornal tem uma preocupação em ser mais popular e acessível que o anterior, o que é explicitado especialmente no recente livro de Carlos Azevedo (2011).

${ }^{10}$ Para os pesquisadores do rádio no Rio Grande do Sul, ficaram famosas as leituras que o locutor Milton Jung fazia, ao microfone da Rádio Guaíba, irônicas ou enfáticas, destacando conteúdos que, muitas vezes, poderiam passar despercebidos ou serem tomados como rotineiros, pelo leitor desavisado.
} 
Em geral, entre uma terça parte e a metade das matérias enviadas, a cada semana, sofriam restrições ou cortes totais por parte dos censores, o que significava que os editores sempre precisavam ter matérias alternativas, de igual peso e qualidade, para substituir àquelas retiradas da publicação e/ou buscar uma redação capaz de, embora dizendo o que fosse pretendido, conseguisse ser aceito ou não compreendido pelo censor.

\section{A América Latina nas páginas de Opinião}

No conjunto das matérias sobre a América Latina, divulgadas por Opinião, a atenção do jornal recai sobre o Chile, que vive a experiência do governo socialista de Salvador Allende. Allende chamara o apoio das Forças Armadas do país, que guardavam uma posição constitucionalista, sempre distantes da política. Enfrentava paros provocados pelos industriais e sofria o boicote explícito da ITT norte-americana, mas as coisas pareciam suficientemente tranqüilas para permitir-lhe uma histórica visita ao Chile de Luis Echeverria e uma chegada às Nações Unidas, em Nova York, quando aproveita para reunir-se com o governo dos Estados Unidos.

Outro país destacado é a Argentina, que vive a experiência da volta do caudilho Juan Perón, enquanto o Uruguai tem em Juan Maria Bordaberry seu atual presidente, que tenta impedir um novo golpe de estado, o que acaba ocorrendo. Um suplemento especial do jornal, em novembro de 1972, destaca e analisa os contextos enfrentados por Argentina, Bolívia, Uruguai, Paraguai e Peru, em ensaios que página inteira da publicação e com textos assinados, dentre outros, por Eric Hobsbawm e Eduardo Galeano.

Como o jornal Opinião é mais dedicado ao artigo de fundo ou ensaio, publica textos como, por exemplo, a análise dos modelos de planejamento seguidos por Brasil, Peru e México, que naquele momento são as principais referências do continente. Ou reflete sobre a presença das empresas multinacionais no continente e suas desastrosas conseqüências. Pode, também, discorrer sobre o vírus peruanista, como denomina a experiência peruana de militares no poder, tentando promover um novo ciclo desenvolvimentista no país, com maior justiça social, mas sendo pressionados e contestados pelos latifundiários e industrialistas nacionais, bem como pelas forças econômicas internacionais, na medida em que tais países dependem de empréstimos do FMI e outras instituições semelhantes para rolarem suas dívidas, agravadas com a crise do petróleo, cujos preços dispararam. Daí que Opinião chega inclusive a dedicar duas páginas a uma entrevista com o 
diretor cinematográfico Costa Gavras, que estava lançando o filme Estado de sítio, reconstituindo presumíveis acontecimentos ocorridos pouco antes no Chile.

De modo geral, a presença latino-americana nas páginas do jornal é pequena: notícias sobre o Haiti de Duvalier; greves nas minas da Bolívia; movimentos de oposição na Guatemala, também sob ditadura; o $192^{\circ}$ golpe de estado na Bolívia, como o jornal intitula sua matéria, etc. Ainda sobra espaço para uma matéria a respeito o crescimento do esporte em Cuba; o futebol do Corinthians que vai enfrentar os times hispano-americanos por uma Copa da América; e a vitória de Emerson Fittipaldi, no Grande Prêmio da Argentina. Afinal, nem só de política e de economia viviam os leitores do jornal.

\section{A América Latina nas páginas de Movimento}

O levantamento do corpus antes citado nos indica que as matérias publicadas se caracterizam enquanto pequenas notícias, em geral editadas em duas colunas, em matérias de cerca de $10 \mathrm{~cm}$. de altura; grandes reportagens de página inteira; dossiês relativos a acontecimentos de maior relevância, incluindo cronologias do acontecimento (casos da Argentina e do Peru, em 1976); e, enfim, as "Notas latino-americanas", alternativa que o jornal encontrou para dar uma cobertura mais ampla ao conjunto de países do continente. Neste caso, as "notas..." podiam ocupar metade de uma página ou estender-se por duas páginas, em uma coluna contínua. Cada matéria se compunha de não mais que dez linhas, sucintas e objetivas, como o noticiário do rádio ${ }^{11}$. Os editores de Movimento sempre se preocuparam em contextualizar e orientar seu leitor, de modo que as matérias se configuram enquanto suítes de informações anteriores (às vezes, o jornal chega a indicar a edição em que anteriormente havia sido informado alguma coisa a respeito ${ }^{12}$ ). No conjunto das edições consultadas, encontramos, ainda, uma espécie de resumo ou balanço dos acontecimentos do ano anterior, sob o título geral de "América Latina 1975", que se edita a partir da edição 28, de 12 de janeiro de 1976.

\footnotetext{
${ }^{11}$ Assim como a internet viria a interferir, décadas depois, no formato dos jornais contemporâneos, será que não era uma influência do rádio o fato de se apresentarem pequenas informações em textos que poderiam facilmente ser lidos por um locutor radiofônico e serem escutadas pelo ouvinte/leitor de jornal, neste caso?

${ }^{12}$ Esta prática, alias, é mais uma a indicar a clara filiação de Movimento à tradição publicística do jornalismo. Lembremos que, por exemplo, o Correio Braziliense, de Hipólito José da Costa, editado desde Londres, previa sua encadernação a cada seis edições (semestre), contendo na última deles até mesmo um índice com as matérias publicadas, prática que perdurará até a última edição, em dezembro de 1822. Pressupõe-se, pois, que o jornal não deve ser apenas lido, mas guardado, refletido e consultado permanentemente como fonte de informação e de reflexão crítica.
} 
A América Latina, já caracterizada por Eduardo Galeano como um continente de "veias abertas", recebe, assim, uma atenção muito especial dos editores do jornal. Para além do interesse que se pretende dar ao continente, coisa incomum nos jornais da camada grande imprensa ${ }^{13}$, há uma evidente preocupação em aproximar este noticiário dos acontecimentos do próprio Brasil. Movimento vale-se de fontes diferentes daquelas que usualmente os jornais da imprensa de referência utilizam, como as agências Latin American News ${ }^{14}$, IPS (Inter Press Service) ${ }^{15}$ ou revistas como Afrique-Asie, Nuevo Hombre e El periodista, além de artigos de pensadores acadêmicos, como Eric Hobsbawm ou Warren Dean.

O jornal mantém, ainda, uma equipe de redatores e colaboradores como responsáveis permanentes por tais informações, de modo que eles podem, não apenas informar quanto interpretar - muitas vezes associar informações diversas - buscando uma ampla contextualização do que está ocorrendo, prática que, evidentemente, a chamada grande imprensa não faz. É o caso daqueles que mais assinam matérias sobre tais acontecimentos, como Ronaldo Brito (que muitas vezes se assina R.B.), Rafael Marko, Lauro Bandeira, Vanda Pinto, Fausto Torres, Flávio de Carvalho: de modo geral, contudo, a maioria das matérias é veiculada sem autoria, o que significa ser um trabalho de redação.

O levantamento realizado nos indica que praticamente todos os países da América Latina foram objeto de preocupação do jornal. A mais destacada, contudo, foi a Argentina. Movimento acompanha, passo a passo, os estertores do regime peronista, depois do retorno e da morte de Juan Perón, em cujo lugar fica sua segunda viúva, Maria Stela Martinez de Perón, chamada Isabelita. O domínio do governo é de "El Brujo" José Lopez Rega, sobre o qual, posteriormente, recairão processos por envolvimento em grandes desvios de dinheiros públicos, contrabando e fomento a organizações para-militares, como a Triple A - AAA - Alianza Anticomunista Argentina. Não é surpresa quando o Exército exige e formação do Conselho de Segurança Interna, que passa a combater frontalmente aos Montoneros e aos integrantes do ERP - Exército Revolucionário del

\footnotetext{
${ }^{13}$ Vários trabalhos recentes evidenciam que os jornais brasileiros continuam ignorando seus vizinhos latino-americanos. E, quando eles são notícia - por desastres naturais ou movimentos políticos que quebram a perspectiva democrática eleitoral formal dessas nações - boa parte do noticiário vem filtrado por agências internacionais, notadamente norte-americanas. Destaco, dentre os trabalhos recentes, A América Latina no jornalismo brasileiro: Os casos de Zero Hora e Folha de São Paulo, de Stéfano Aroldi Santagada, Porto Alegre, FAMECOS. 2011. Mimeo.

${ }^{14}$ Mais conhecida como Prensa Latina, foi criada em 1959, por iniciativa de Ernesto Che Guevara, logo após a vitória da Revolução Cubana, e inicialmente organizada pelo jornalista argentino Jorge Ricardo Masetti. Trabalharam nela, dentre outros, Gabriel Garcia Marquez, Rodolfo Walsh, Leonardo Acosta, etc.

${ }^{15}$ A IPS foi fundada em 1964 pelo economista Roberto Savio e pelo cientista político Pablo Piacentini, ambos argentinos, com o objetivo de trabalhar temas como o desenvolvimento social, defesa ambiental e direitos humanos. Sua formação original era cooperativada.
} 
Pueblo, e que em breve voltar-se-á também contra os sindicatos mais combativos. Mas a situação chegou a um limite extremo e, em 23 de março de 1976 nada mais havia a fazer, se não fechar a CGT e os sindicatos independentes, prender lideranças e afastar Isabel do comando político: o General Videla, que já exercia, de fato, o controle da situação, torna-se então o mandatário do país.

Outros países merecem especial cobertura de Movimento, como o México, cujo governo de Luis Echeverria se encerra, sendo sucedido por José Lopes Portillo; a Venezuela, que vive a euforia dos altos preços do petróleo, sob a administração de Carlos Andrés Perez, então considerado crescentemente afastado de suas promessas reformistas de campanha. O Peru experimenta uma ditadura militar de esquerda, mas o General Alvarado já foi deposto pelo General Morales Bermudez que, por sua vez, enfrenta igualmente dificuldades, tendo que se equilibrar entre as necessárias reformas sociais, que incluem o difícil segmento agrário do país, e as pressões internacionais, na medida em que o Peru necessita de empréstimos para gerir sua dívida. O jornal acompanha, enfim, o que vai chamar de retificação da revolução, ou seja, uma definitiva opção pelo conservadorismo, o que gera decepções. Contudo, a vizinha Bolívia vive o mesmo dilema: o General Hugo Banzer enfrenta latifundiários e industriais conservadores que se opõem a seus planos reformistas. A Bolívia luta, por outro lado, para conseguir um corredor de saída para o Pacifico, negociando com o ultra-direitismo regime chileno. Quanto ao Equador, o general Rodriguez Lara está imprensado entre a hierarquia da Igreja Católica conservadora e as crescentes reivindicações dos sindicatos, enquanto busca a institucionalização do regime. Mas é obrigado a manter a imprensa sob censura, acabando por ser substituído pacificamente no comando governamental por um Conselho administrativo.

O Uruguai está sob o comando de Juan Maria Bordaberry, que enfrenta problemas. O Chile sofre sob a radical ditadura de Augusto Pinochet. No Panamá, enquanto isso, o General Omar Torrijos começa a elevar o tom de voz em torno das negociações sobre o futuro do Canal do Panamá, o que, na avaliação de alguns jornalistas, poderia transformar a região num novo Vietnã. Os Estados Unidos parecem querer negociar com Cuba. O ditador do Paraguai faz uma aproximação estratégica com a África do Sul, ainda sob o regime do apartheid. Movimento cobre as tentativas de definição de rumos do recentemente independente Suriname; a Guatemala não enfrenta apenas terremotos, mas problemas políticos internos, graças à herança terrível que a marca sob a dominação de multinacionais norte-americanas, como a United Fruit. 


\section{Considerações finais}

Retomando o que antecipamos antes, teoricamente, a respeito dos dispositivos apresentados pelos jornais, pode-se dizer que Opinião e Movimento fazem pleno uso de alguns deles: reúnem numa mesma página diferente noticiário a respeito da América Latina. Isso é ainda mais enfatizado através de suplementos específicos ou, no caso de Movimento, das "Notas latino-americanas", pequenas informações reunidas numa mesma página: tal procedimento evidencia a unidade de ponto de vista que deve ter o leitor a respeito de tais acontecimentos, apresentados, não como fatos isolados, mas como parte de certa narrativa que segue determinada lógica que resulta da dominação política e econômico-financeira. Opinião gosta de incluir o nome do país no título da matéria. Em Movimento, cada matéria é encabeçada, normalmente, por um chapéu com o nome do país. Tais práticas levam a uma perspectiva de compreensão diversa, já que, no primeiro caso, enfatiza o tema e, no segundo, a origem da informação.

No caso de Opinião, pode-se depreender certo otimismo a respeito dos acontecimentos. Movimento evita qualquer tendenciosidade, limitando-se a informar e, pragmaticamente, associar os fatos narrados uns com os outros.

Essa organização temporal/espacial evidencia o acerto da proposta de estudo de Maurice Mouillaud, pois de certo modo predispõe a leitura diferenciada e crítica de tais acontecimentos por parte do leitor que se pretende mais atento e bem informado dos jornais Opinião e Movimento: pode-se identificar um discurso que atravessa todo o conjunto de textos publicados. Enquanto os governos latino-americanos - alguns de esquerda, ainda que formados por militares - tentam a independência sócio-econômica de seus países, as multinacionais, notadamente as dos Estados Unidos, atuam mancomunadas com os latifundiários e entreguistas para prejudicar a grande sociedade latino-americana que tem, assim, uma grande identidade: a luta pela liberdade.

Eis porque pareceu oportuno refazer a leitura de jornais como Opinião e Movimento: infelizmente, o panorama pouco mudou de lá para cá, mas a luta e a resistência continuam sendo fundamentais. Opinião e Movimento, enquanto jornais vinculados à perspectiva do publicismo inglês, mesmo enfrentando os difíceis tempos da ditadura brasileira pós AI-5, buscaram cumprir seu papel, não apenas informando - o que já seria extremamente importante - quanto formando e 
ajudando a constituir uma opinião crítica no Brasil, junto a uma geração que, em última análise, é aquela que hoje responde diretamente pelo presente de nosso país.

\section{Referências}

ABREU, Alzira Alves de (Org.). A democratização no Brasil: atores e contextos, Rio de Janeiro: Fundação Getúlio Vargas, 2006.

AGUIAR, Flávio. Censura e cultura em Movimento. In: CARNEIRO, Maria Luiza Tucci (Org.). Minorias silenciadas. São Paulo: EDUSP/IOESP/ FAPESP, 2002. p. 403 - 417.

ALBIN, Ricardo Cravo. Driblando a censura: de como o cutelo vil incidiu na cultura. Rio de Janeiro: Grfyphus, 2002.

AZEVEDO, Carlos; AMARAL, Marina; VIANA, Natália et al. Jornal movimento: uma reportagem. Belo Horizonte: Manifesto, 2011.

CAPARELLI, Sérgio. Comunicação de massa sem massa. São Paulo: Cortez, 1976.

CARNEIRO, Maria Luiza Tucci (Org.). Minorias silenciadas: história da censura no Brasil. São

Paulo: EDUSP/FAPESP/ Imprensa Oficial de São Paulo, 2002.

GALEANO, Eduardo. Las venas abiertas de América Latina. México: Siglo XXI, 1971. p. 3.

GROTH, Otto. O poder cultural desconhecido: fundamentos da ciência dos jornais. Tradução e seleção do original Die Unerkannte Kulturmacht. Greendlengung des Zeitungwissenschaft.

Petrópolis: Vozes, 2011.

HOHLFELDT, Antonio. Relações entre jornalismo e literatura na década dos 70. In KOHUT, Karl (Ed.). Palavra e poder: os intelectuais na sociedade brasileira. Vervuert Verlagf: Frankfurt AM Main, 1991. p. 125-139.

HOHLFELDT, Antonio. A fermentação cultural da década brasileira de 60. In: MELO, José Marques et al. GOBBI, Maria Cristina (Orgs.). Gênese do pensamento comunicacional latinoamericano: O protagonismo das instituições pioneiras: CIESPAL, ICINFORM, ININCO. São Bernardo do Campo: Universidade Metodista de são Paulo/Cátedra UNESCO de Comunicação, 1999. p. 59-91. O mesmo artigo se encontra reproduzido, parcialmente modificado, como "A fermentação cultural da década brasileira de 60", em Porto Alegre, Revista FAMECOS, v. 11. 1999, p. 38-56.

HOHLFELDT, Antonio; MANZANO, Júlia et al. O cinema brasileiro nas páginas de Movimento: autonomia da indústria nacional e defesa da cultura popular. In: Encontro da COMPOS, 18., 2011, Porto Alegre. GT Cultura e Comunicação. Porto Alegre: UFRGS, jun. 2011. Publicado, com revisão, em Revista FAMECOS, Porto Alegre, v. 18, n. 2. 2011.

MACHADO, José Antonio Pinheiro. Opinião x censura. Porto Alegre: L\&PM, 1978. MAIA, Maurício. Censura, um processo de ação e reação. In: CARNEIRO, Maria Luiza Tucci (Org.). Minorias silenciadas. São Paulo: EDUSP/IOESP/ FAPESP, 2002, p. 469-511. MARCONI, Paolo. A censura política na imprensa brasileira. São Paulo: Global, 1980. MARQUARDT, Eduard. Os limites regrados da oposição. In: Opinião 1972-1973. Disponível em: <www.cce.ufsc.br>. Acesso em: 21 out. 2011.

MATTOS, Sérgio. Mídia controlada: a história da censura no Brasil e no mundo. São Paulo, Paulus. 2005.

MELO, José Marques de. A opinião no jornalismo brasileiro. Petrópolis: Vozes, 1985.

Comun. \& Inf., v. 15, n. 1, p. 06-20, jan./jun. 2012 
MELO, José Marques de. Gêneros jornalísticos na Folha de São Paulo. São Paulo:

Summus/USP, 1987.

MELO, José Marques de. Síndrome da mordaça: mídia e censura no Brasil. São Bernardo do Campo: Universidade Metodista de São Paulo, 2007.

MOUILLAUD, Maurice; PORTO, Sérgio Dayrell et al. (Orgs.). O jornal: da forma ao sentido. Brasília, UNB. 2002. p. 29 - ss.

RIBEIRO, Sabrina. Fernando Gasparian: um empresário que nunca se vendeu. Disponível em: <www.anovademocracia.com.br>. Acesso em: 21 out. 2011.

RÜDIGER, Francisco. Tendências do jornalismo. Porto Alegre: Ed. da UFRGS, 1993. p. 11.

RÜDIGER, Francisco. Introdução à teoria da comunicação. São Paulo: EDICON, 1998. p. 11.

SOARES, Gáucio Ary Dillon. Censura durante o regime autoritário. Disponível em:

<www.anpocs.org.br>. Acesso em 21 out. 2011.

SMITH, Anne-Marie. Um acordo forçado: o consentimento da imprensa à censura no Brasil. Rio de Janeiro: Fundação Getúlio Vargas, 2000.

Comun. \& Inf., v. 15, n. 1, p. 06-20, jan./jun. 2012 